\title{
A démarche stratégique (gestão estratégica hospitalar): um instrumento de coordenação da prática hospitalar baseado nos custos de oportunidade e na solidariedade
}

The hospital strategic management: one regional coordination mean of hospital practice based on opportunity costs and solidarity

Elizabeth Artmann 1

Francisco Javier U ribe Rivera 1

1 Departamento de Administração e Planejamento, EN SP, Fiocruz. Rua Leopoldo Bulhões 1480, 70 andar, M anguinhos, 21041-210, Rio de Janeiro RJ. artmann@ensp.fiocruz.br

\begin{abstract}
This text is a general presentation of the hospital strategic management methodology elaborated by M. Crémadez and F. Grateau (France), including the goals, phases and main tools of the approach. The work takes into account the microeconomic aspects of the methodology and its potentials to stucture health care networks based on negotiation of hospitals goals. The text includes the presentation of one experience of implementation of the approach as a regional coordination mean applied by general surgery discipline of programatic area (AP-4) hospitals of Rio de Janeiro city.
\end{abstract}

Key words Strategic planning, H ospital management, health care profile, Public health
Resumo Este texto é uma apresentação geral da metodologia de gestão estratégica hospitalar de M. Crémadez e F. Grateau (França), incluindo os objetivos, as fases e as principais ferramentas do enfoque. 0 trabalho destaca os aspectos microeconômicos do mesmo e suas possibilidades para estruturar redes de serviços através da pactuação de metas e objetivos entre hospitais. Inclui a apresentação de um caso de aplicação do enfoque como instrumento de coordenação regional da especialidade de cirurgia geral dos hospitais de uma área programática (AP-4) da cidade do Rio de Janeiro.

Palavras-chave Planejamento estratégico, Gestão hospitalar, Perfil assistencial, Saúde pública 


\section{Introdução}

A presenta-se neste artigo a lógica da démarche stratégique, enfoque de gestão estratégica hospitalar trazi do da França, adaptado e aplicado experimentalmente no Brasil (Rivera, 1997; Souza, 1997; Lopes, 1997; Artmann, 2002). As potencialidades do enfoque como instrumento de colaboração hospitalar, a serviço da pactuação da missão dos vários estabelecimentos hospitalares de uma rede, são exploradas de forma a mostrar a coerência com o movimento de descentralização desencadeado pela expansão e intensificação do projeto municipalista (N OB 01/93 e NOB 01/96) e mais recentemente com a N orma O peracional de Assistência à Saúde - NOAS 01/2002, que preconiza uma estratégia de desenvol vimento da política de saúde no Brasil no sentido de avançar na construção das bases de um sistema regionalizado e hierarquizado.

0 enfoque em pauta propõe-se a organizar redes de colaboração que substituam a concorrência (não justificada, com falta de coordenação, que se traduz em disputa por clientela ou por recursos/investimento) pela busca da complementaridade. Para tal, apóia-se numa análise estratégica de base microeconômica, que se traduz na definição de estratégias combinadas de custos e de diferenciação, relativas aos vários segmentos de produção de um hospital, e na busca e aprofundamento de uma rede de sinergias internas e parcerias externas que otimizem a utilização de recursos dentro das premissas de co-responsabilidade pelos cuidados e de solidariedade no emprego de recursos não elásticos.

Considera-se esse instrumento essencialmente comunicativo e exigente em estratégias de negociação. Visa oferecer subsídios para o desenho da missão hospitalar e formulação de proje tos a partir das especialidades médicas, tendo em vista a inserção do hospital na rede de assistência mais ampla. É essencial ao alcance da coordenação como objetivo da gestão a capacidade de servir de instrumento de diálogo, de pactuação das missões das diferentes instituições e das estratégias de desenvolvimento. Pode oferecer elementos para pensar sua utilização adaptada como apoio à PPI (Programação Pactuada Integrada) a partir de sua concepção como instrumento de planejamento/programação regional. É condição básica para o alcance desse objetivo que os hospitais sejam cobrados em relação à formulação de projetos institucionais que sirvam de base para estabelecer contratos de gestão externos einternos, incluindo outros atores e a regulação.
Este trabalho está estruturado de maneira a apresentar os grandes objetivos do método, sua lógica de análise estratégica e as grandes estratégias que marcariam o desenvolvimento dos segmentos de produção das especialidades hospitalares, aproveitando o modelo adaptado de Porter por Crémadez (1992; 1997). Dá-se especial ênfase às estratégias fundadas na diferenciação e nos custos, refletindo a incorporação de conceitos da economia da saúde, embora o método também considere outras dimensões como a cultura, a intersecção entre critérios epidemiológicos, mais objetivos e outros, mais subjetivos, na valorização dos segmentos a serem priorizados e a necessi dade de visão interdisciplinar (Artmann, 2002). Apresenta-se, ainda, de forma concisa, a experiência de aplicação do enfoque como instrumento de coordenação regional desenvolvida na Área de Planejamento 4 (AP-4), no Rio de Janeiro (Artmann, 2002). E por fim comenta-se a utilidade eventual da démarche no contexto da NOAS.

\section{Os grandes objetivos do enfoque}

A démarche é um método desenhado para o setor público, que supõe a adaptação de um enfoque empresarial (Artmann, 2002a). Esse enfoque de planejamento/gestão estratégica hospitalar se apóia em elementos da microeconomia, do campo da estratégia e da política, e da área do desenvolvimento organizacional e cultural; introduz al gumas categorias próprias da área de saúde e da epidemiologia, reconhecendo também a especificidade do setor público de saúde, na França. Está baseado em autores como $\mathrm{H}$ enry Mintzberg (1982), Michel Crozier e Erhard Friedberg (1977), Michel E. Porter (I982), M aurice Thevènet (1993), entre outros.

Esse enfoque propõe-se a definir racionalmente a missão de um hospital, situando-o na perspectiva ideal de uma rede coordenada de serviços de saúde (Crémadez e Grateau, 1992; 1997). N esse sentido a organização hospitalar é compreendida como uma organização pró-ativa, centrada sobre 0 exterior, que assume 0 ambiente como recurso e não como restrição. Isso significa que a definição da missão terá que ser negociada com o ambiente externo institucional incluindo os outros hospitais da área à qual pertence. Destaca-se, então, a capacidade pró-ativa da organização e sua atuação dinâmica sobre o ambiente.

As características das organizações de saúde tendem natural mente para um padrão que 
se distancia de um ideal representado pela aplicação de critérios de racionalidade econômica da missão, pela concepção do ambiente externo como recurso e por uma maior integração intra-institucional. N esse padrão apresentado pelas organizações de saúde e analisado com mais profundidade adiante, destacam-se os traços característicos: um processo de autonomização dos centros operacionais, decorrente de uma sorte de ruptura entre a direção estratégica e estes últimos, uma extrema diferenciação ou atomização de suas estruturas internas em função da especialização do trabalho, e uma desconsideração relativa da ambiência externa em razão de uma sobrevalorização corporativa do interno. Traços esses que conspiram contra a possibilidade de um projeto gerencial que enfatize a integração intra-institucional, a racionalidade econômica da missão específica e a negociação de uma rede de cuidados com os outros estabelecimentos da ambiência imediata. A perspectiva da démarche é a de promover um tipo de movimento cultural que contrabalance essas tendências, abrindo caminho para o desenvolvimento de uma forma de organização que se aproxime daquelas premissas ideais (Rivera, 1997; Artmann, 2002a).

Em grandes linhas, os objetivos da démarche seriam:

- promover um elo entre a gerência estratégica e os centros assistenciais, através da comunicação;

- definir a missão do hospital de acordo com o critério de oportunidade, que corresponde a determinar preferencialmente um padrão de atividades que Ihe permita vantagens comparativas ao mesmo tempo em que ofereça um serviço de qualidade aos usuários (entenda-se por vantagem comparativa a possibilidade de atrair relativamente mais clientela pela percepção que a mesma teria da superioridade de sua oferta);

- ensejar um lugar de comunicação, onde os atores-serviços possam chegar a definir um projeto coletivo;

- favorecer a integração do hospital em uma rede de oferta de cuidados estruturada com a preocupação da eficácia e da eficiência;

- promover um processo de transformação cultural progressiva, não necessariamente preso à busca de objetivos instrumentais, imediatos.

Esse enfoque questiona uma visão monolítica da excelência, representada pela intenção de cobrir todas as áreas de atendimento, apoiando-se numa estratégia microeconômica. A alternativa a essa visão seria a de trabalhar a vo- cação de cada estabelecimento na perspectiva da complementaridade. A melhor estratégia para que um estabelecimento possa obter vantagens comparativas é a diferenciação (Porter, 1982), que pressupõe a distinção de suas áreas de excelência ou competências distintivas, assim como das áreas em que atua relativamente pior do que os outros estabelecimentos, com o objetivo de priorizar internamente o desenvolvimento das primeiras e de negociar as segundas com a rede de serviços. A opção nuclear do enfoque é a idéia de procurar transformar a concorrência frontal em colaboração, através da busca e aprofundamento das competências distintivas de cada hospital e da negociação das missões entre os diferentes estabelecimentos. Em contraposição à idéia de que todas as instituições ofereçam todos os serviços, essa opção pode contribuir para permitir maior acesso da população a serviços diferenciados e de alto nível de qualidade.

Da perspectiva político-organizacional, 0 enfoque aposta na via da responsabilização dos atores, que implica o desenvolvimento de processos comunicativos e de negociação internos e externos, que redundem em acordos relativos aos projetos assistenciais pertinentes a uma rede, opondo-se a uma definição normativa e tecnocrática de diretrizes. No que se refere à estrutura organizacional, o enfoque postula a necessidade de intensificar as estruturas em rede interna e o diálogo multidisciplinar, promovendo a busca de transversalidades (Rivera, 1998; Artmann, 2002; 2002a).

\section{0 método}

As fases do método e seu conteúdo geral são as seguintes:

- A análise do existente - corresponde ao diagnóstico administrativo e médico.

- A segmentação - corresponde à definição dos principais agrupamentos homogêneos de atividades, considerados como aqueles que apresentam uma mesma problemática estratégica.

- A análise estratégica propriamente dita correspondeà análise do valor e da posição competitiva de cada um dos segmentos resultantes dos agrupamentos de atividades: 1) o valor se refere ao interesse relativo ou ao nível de prioridade relativo que os segmentos teriam para a especialidade, em função de uma política geral, e se expressa pelo interesse em Ihes alocar recursos. U m critério genérico na aferição desse va- 
Ior está representado pela capacidade potencial de atração de clientela ofertando um atendimento de excelência, com eficiência; 2) a posição competitiva é avaliada considerando-se o grau de controle sobre os chamados FatoresChave de Sucesso (FCS), que corresponderiam a vantagens ou situações positivas necessariamente controladas para a garantia de êxito em uma atividade. Para estimar o valor e a posição competitiva dos segmentos se usa um sistema de notação, de 0 a 20.

- A construção do portfolio de atividades, concebido como um documento importante para definição da estratégia geral de atuação ou dos objetivos específicos em face dos segmentos: 0 portfolio é um gráfico cuja abscissa está representada pela posição competitiva do estabelecimento e a ordenada pelo valor dos segmentos. U ma terceira variável do portfolio é o volume de produção dos segmentos, que corresponde ao tamanho das bolhas que tipificam os segmentos num gráfico pertinente.

- O Plano de Ação visando atingir os objetivos que compõem a estratégia, definidos em termos de três possibilidades: 1) priorizar o desenvolvimento de um segmento; 2) estabilizáIo; 3) reduzir o recrutamento de clientela ou recortar o segmento. No Brasil temos identificado também a estratégia de inovação ou criação de novos segmentos devido ao reconhecimento de necessidades não atendidas (Artmann, 2002a). - A montagem dos indicadores de monitoramento do plano.

0 diagnóstico é duplo - administrativo e médico - , voltado para subsidiar a definição da segmentação. 0 diagnóstico médico compreende: a listagem das patologias e das tecnologias do serviço; o cruzamento das patologias e tecnologias; a classificação das patologias e tecnologias segundo vários critérios gerenciais, como a eletividade dos atos, a necessidade de tratamento ambulatorial e/ou de internação, a duração da internação e o caráter interno ou externo das tecnologias utilizadas. A análise do existente inclui também a listagem de parceiros e concorrentes e uma análise da distribuição da oferta de atividades por especialidade entre os vários hospitais de uma área que contam com a mesma.

A segmentação estratégica é um processo situacional, no sentido matusiano do termo (Artmann, 2000), em que se procura definir grupos homogêneos de atividades através de quatro critérios possíveis: patologia; tecnologia; tipo de atendimento; e população. Alguns desses critérios são adotados preferencialmente, embora sempre coexistam vários deles marcando a segmentação. A segmentação é orientada estrategicamente na medida em que o recorte delineado tende a apresentar grupos de atividades que permitiriam vantagens comparativas, ou atividades de referência. $\mathrm{O}$ u seja, na segmentação destacamos áreas de atividades que implicam uma oferta singular, de vanguarda. Por exemplo, define-se em geral um segmento por tecnologia quando se trata de técnicas e equipamentos de uma certa complexidade, de uso não indiscriminado, que englobam um conjunto característico de patologias e que constituem competências distintivas ou "exclusivas".

A análise do valor é feita prospectivamente através da aferição de vários critérios de cálculo (UAS-CHRU:1995a, b). Dentre eles, destacamse os seguintes:

- O critério oportunidade de crescimento do segmento, que expressa a demanda potencial decorrente da evolução epidemiológica e social da população e da evolução tecnológica. Segundo este critério, priorizam-se relativamente segmentos que apontam para um crescimento re lativamente maior.

- 0 critério intensidade da concorrência, que implica desvalorizar segmentos compartilhados por uma concorrência potente e diversificada quantitativamente.

- 0 critério investimento realizado ea realizar (em capacidade instalada, recursos humanos especializados e em equipamentos tecnológicos), tendo em vista um al to investimento considerado necessário para vingar no segmento. A aproximação do investimento realizado e em vias de realizar do padrão necessário sugereuma alta valorização do segmento relativo, pois esta situação comporta vantagens comparativas potenciais em relação a concorrentes eventuais. Considera-se que fica difícil para concorrentes eventuais entrar em um segmento onde já existem instituições com um alto investimento relativo prévio. - O potencial de sinergias (integrações com outros segmentos do mesmo hospital) e parcerias externas (integrações com segmentos de outros hospitais) tipificam critérios que contribuem para valorizar aqueles segmentos de mai or potencial, na medida em que esse potencial expressaria o compartilhamento de recursos e a complementaridade de esforços, que redundam em economia de custos e em melhoria de qualidade.

- A possibilidade de trazer mais recursos econômicos também contribuiria para valorizar segmentos. 
- A capacidade de incorporar e de transferir tecnologia podem também ser considerados critérios de valorização relativa importante de segmentos.

Esses critérios conjugados sugerem priorização de segmentos que ensejem a captação de um volume importante de clientela, dentro de uma política de racionalização de recursos econômicos e de busca da qualidade no atendimento às demandas/necessidades de saúde. Chama a atenção, do ponto de vista microeconômico, 0 interesse em priorizar segmentos onde a concorrência (em termos de clientela ou de recursos) seja pequena, permitindo maiores fatias de mercado, assim como segmentos onde o investimento corresponda a um nível de concentração que aponte para uma condição de referência. Definir as instituições nas quais determinados segmentos concentram um alto enecessário investimento corresponde a buscar uma política de economias de escala.

A avaliação da posição competitiva corresponde a uma análise da governabilidade dos segmentos, entendida como o grau de controle atual dos Fatores-Chave de Sucesso (FCS), que são capacidades tecnológicas, profissionais, relacionais e financeiras, as quais seria necessário controlar para se destacar em termos de desempenho relativo. Um baixo nível de controle dessas capacidades não significa que um determinado segmento deva ser abandonado. Isso dependerá de seu valor, em função do qual se poderá recomendar, ou não, um processo de apropriação de FCS. É importante destacar que alguns FCS operam como critérios da análise do valor, como o próprio potencial de sinergia e de parceria externa que valorizam um segmento e, especialmente, o investimento em capacidade tecnológica e profissional, de modo que alguns critérios das duas dimensões da análise estratégica se cruzam. N esse particular, a análise da posição competitiva, que deve ser comparativa, no sentido da identificação do controle dos FCS pelos parceiros e concorrentes, ajudaria a discernir as competências distintivas de cada hospital.

O Portfolio de Atividades, constituído a partir das variáveis anteriores (valor e posição competitiva) e do volume de produção dos segmentos, permitiria comparar a posição relativa dos vários segmentos e definir em função da mesma a estratégia necessária. 0 portfolio serve para determinar prioridades, para fixar a estratégia do hospital em termos de três possibilidades de objetivos, principalmente:
- Desenvolver um segmento: identificar as atividades que devem ser expandidas, priorizadas, desenvolvidas particularmente. Este objetivo em geral se confunde com a estratégia de diferenciação ou de agregação de um plus de valor percebido como melhora de qualidade, podendo implicar mais custos, em investimentos específicos para enfrentar os pontos fracos típicos dos FCS. 0 desafio aqui seria buscar a estratégia de diferenciação que envolvesse relativamente menos custos.

- M anter ou estabilizar um segmento: definir os segmentos que devem ser mantidos em "banho-maria", no mesmo nível de desenvolvimento histórico e, se possível, reduzindo custos. Aqui podem constar segmentos de alta competitividade e valor, os quais poderiam ser apenas mantidos na atual posição, reduzindo custose liberando recursos para outras atividades.

- Reduzir o recrutamento da clientela para um segmento: definir qual seria necessário recortar ou focalizar, desestimular, diminuir, negociando a transferência parcial ou total de atividades para a rede (entende-se por focalização privilegiar um determinado tipo de usuário ou nosologia).

Para Porter (1982), haveria três estratégias genéricas, melhor discutidas adiante a partir da obra de Crémadez e Grateau (1992;1997): diferenciação, que implicaria definir uma oferta única, exclusiva, diferenciada, percebida por todos como superior qualitativamente, cujo acesso também poderia ser diferenciado; liderança no custo, que representaria diminuir custos para liberar recursos para outros segmentos, sem comprometer a qualidade; focalização (que pode integrar-se como estratégia de custos e/ou diferenciação)

O Plano de Ação é o "que fazer" para imple mentar a estratégia. Consistiria em um conjunto de atividades, tais como:

- Formas de apropriação/desenvolvimento dos Fatores-Chave de Sucesso visando enfrentar os pontos fracos identificados na análise de incorporação de tecnologias e de recursos humanos, treinamentos, desenvolvimento de fatores de qualidade, etc.

- Ações de negociação e de comunicação internas ao hospital e com a rede, incluindo o estabelecimento de sinergias e parcerias externas. - Ações visando revalorizar um segmento, atuar sobre al gum critério da análise do valor de baixo escore, passível de intervenção (quando a decisão política é de buscar aumentar o valor). 
- Ações visando modificar o modelo assistencial, as formas de atendimento que caracterizam um determinado segmento, o perfil de tecnologias utilizadas.

- Ações de natureza social e intersetorial.

- Ações que desenvolvam objetivos tipicamente médicos, como determinadas pesquisas.

A consolidação de um plano de ação é um contínuo retomar da análise estratégica do valor e da posição competitiva, visando aumentar o controle dos FCS, para melhorar a posição estratégica geral.

O plano culmina com a definição dos indicadores de monitoramento das ações para que seja possível acompanhar as mudanças propostas.

É importante reiterar que do ponto de vista microeconômico o processo defixação de prioridades inerente a este enfoque obedece a um raciocínio de custo-oportunidade. Esse modelo de gestão estratégica introduz o raciocínio dos custos de oportunidade ao levar em conta as necessidades dos outros e o grau de satisfação global obtido pela organização. A aplicação de um recurso a um segmento de atividade deve ser justificada pelo maior ganho comparativo atingido relativamente a usos alternativos. I sso corresponde a priorizar segmentos de maior valor relativo, incluindo uma menor concorrência potencial e um al to investimento necessário realizado ou previsto. As diferenciações, representadas pelo aprofundamento de competências distintivas, que se confundem com esses segmentos, são estimuladas na medida em que se subordinam a uma perspectiva de maior eficiência e eficácia globais, considerando o sistema ou a rede.

U ma das características mais notáveis do modelo de gestão estratégica baseado nos custos de oportunidade é a exploração da diversidade, pois ensina a aceitar a possibilidade de abandonar a posse de uma tecnologia ou de um equipamento, quando estes não constituem competências distintivas de um serviço ou do hospital, e quando a eles se tem acesso pelas sinergias e parcerias, de modo a se concentrar no estudo de formas alternativas de tipo de atendimento que podem valorizar o serviço e, ao mesmo tempo, ser úteis para os usuários.

A gestão estratégica introduz, como se identificou na análise do valor, a necessidade de estimular projetos que permitam a captação de recursos adicionais, via projetos de pesquisa com obtenção de recursos através de órgãos financiadores, o que pode ajudar a limitar con- flitos de poder e a viabilizar projetos que, de outra forma, teriam que ser abandonados ou adiados.

Como foi formulado pelos autores da démarche, a gestão estratégica pretende, assim, arbitrar pelos custos de oportunidade para criar uma solidariedade. Isso significa preferir expandir segmentos de grande potencial de diferenciação, de baixa concorrência, que contam com acúmulos prévios significativos de investimento tecnológico e em capacidades profissionais (ou com a previsão realística dessas possibilidades) que fundamentam redes definidas por sinergias e parcerias externas e por políticas de colaboração que supõem a mobilização mútua de clientela segundo o reconhecimento das capacidades distintivas de cada hospital. $\mathrm{N}$ ão se trata de pensar rigidamente em pseudomonopólios complementares, pois se admite a duplicação de segmentos de atividade segundo as necessidades da demanda. Reconhece-se, porém, que um hospital não deveria promover todo tipo de atividades, mas acrescentar a uma base clínica geral um determinado nível de especialização induzido pelo reconhecimento das capacidades distintivas, apostando na pactuação sistêmica, na negociação de redes de solidariedade.

A construção da solidariedade depende acima de tudo da clara distinção na análise estratégica da segmentação das sinergias e parcerias potenciais, de modo a fundamentar a escolha de problemáticas transversais que redundem em projetos dinâmicos de integração horizontal, que compensem a diferenciação ou fragmentação e ajudem a totalizar a organização.

A análise estratégica contém uma característica essencial, qual seja considerar o ambiente externo recurso potencial, com o qual se possa formular uma estratégia de cooperação permanente.

Como já salientado, um dos objetivos estratégicos do enfoque em pauta éo estabel ecimento de redes de cooperação interna e externa, e um tipo de estrutura organizacional coerente com essa perspectiva.

Crémadez e Grateau (1992; 1997) reconhecem a possibilidade de quatro tipos de cooperação eventual. N esse sentido recriam, para o contexto sanitário, as formas de aliança estratégica definidas no texto sobre política geral de empresa: Stratégie, structure, décision, identité, do grupo Strategor (1997). Esses tipos são os seguintes: - Parceria vertical - corresponde a coordenar os papéis dos estabelecimentos no seio de um 
mesmo processo de prestação de cuidados. Por exemplo, integração entre os níveis primário, se cundário e terciário de um determinado domínio de atividade (implantação de um sistema de referência e contra-referência materno-infantil). - Integração conjunta - corresponde ao compartilhamento de uma tecnologia, especialmente de recursos raros (diagnóstico e terapia). Aqui, sem acabar completamente com a concorrência virtual mente existente, congela-se um elemento da mesma.

- Adicionamento ou acréscimo - neste caso, não há mais concorrência. Articulam-se estabe lecimentos ou unidades em torno de serviços completos. Há a constituição de um potencial comum. Por exemplo, a organização de pesquisa multicêntrica. Aqui a concorrência virtual cede lugar à competição interna.

- Complementaridade - consiste na valorização das contribuições complementares, na geração de uma prática diferenciada útil para todos os cooperantes. Exemplo, cooperação entre re des de cuidados, entre a medicina e a geriatria, substituindo a concorrência pela cooperação.

A démarche reconhece a possibilidade e necessidade de to das essas alianças estratégicas, dando grande relevância à complementaridade, enten dida como a cooperação entre segmentos e especialidades do mesmo hospital e do hospital e da rede onde se processa um apoio mútuo, representado pelo compartilhamento de recursos físicos, tecnológicos e humanos e de saber e pela plena disposição para estruturar uma rede permanente e vasta de complementaridade.

É importante resgatar a idéia de que o processo de integração estratégica do enfoque em questão não se coaduna com uma visão monolítica da saúde pública, representada pela proposta de um único modelo de integração incutido pela regulação central, considerado um modelo de otimização. A rede deve ser vista como o resultado da imbricação das oportunidades de diferentes formas de cooperação de que se ofere cem aos atores que compõem um sistema. É um conceito que repousa sobre a capacidade de negociação e contratualidade dos atores, já referida. 0 papel da regulação seria o de incitar, ativar e coordenar esse processo de aproximação e de relacionamento, respeitando a diversidade. N esse particular, a via da responsabilização dos atores nada tem a ver com um tipo pesado de planificação tecnocrática (Rivera, 1998).

\section{A conquista de vantagens concorrenciais: estratégias genéricas}

Quando se detém a primazia de uma competência que é fundamental para se ter êxito em um dado segmento de atividade, dispõe-se de uma vantagem determinante sobre seus concorrentes. A vantagem concorrencial se fundamenta no fato de que os usuários (pacientes ou serviços que os referenciam) reconhecem na oferta de um dos concorrentes um valor suficiente para recorrerem a ele. Esse reconhecimento diferencial de valor corresponde, em geral, à percepção de uma maior qualidade relativa, pela qual o usuário se disporia inclusive a pagar um preço maior. Em circunstâncias em que a realidade de preços não impera, pode-se apreciar o valor concedido a um serviço pelos esforços feitos pela clientela para ter acesso a ele (deslocamento, espera consentida, etc.).

Para aumentar a base de vantagens concorrenciais disponível, duas estratégias gerais podem ser seguidas: aumentar o valor para o usuário ou envolver menos recursos sem, no entanto, diminuir o valor do serviço, tal como percebido pelo usuário em termos de qualidade.

A estratégia de diferenciação supõe a possibilidade de criarmos um acréscimo de valor superior ao custo suplementar envolvido para esse fim. A estratégia dos ganhos em eficiência supõe que sejamos capazes de racionalizar a produção de tal maneira que a qualidade não seja afetada e que essa racionalização gere um ganho de recursos suficiente para que sua realocação produza uma vantagem estratégica dominante.

Destaca-se a importância de uma visão analítica dos processos de criação de valor no interior de uma instituição e de suas interações para detectar as fontes de vantagens concorrenciais, o que supõe analisar sua cadeia de valor e a estrutura de custos correspondente. 0 termo cadeia de valor (oriunda de M. Porter) corresponde à descrição das atividades que a organização implementa para realizar e colocar à disposição dos clientes seus produtos ou serviços.

Nesse sentido, vários tipos de atividades podem ser considerados:

- As atividades operacionais principais são todas aquelas que concorrem principal e diretamente para a realização do serviço. Estas atividades podem ser mais ou menos específicas de um segmento ou serem compartilhadas entre vários, como é o caso da estrutura tecnológica relativa aos setores de imagem e de biologia, por exemplo. Estas tecnologias se organi- 
zam em torno de processos de atendimento mais ou menos formalizados, precisos e controlados. A concepção e a condução desses processos deveriam estar no centro da reflexão sobre ganhos em eficiência e em valor. Ora, esta dimensão totalmente dependente da experiência dos profissionais (médicos e paramédicos) não costuma ser objeto de intercâmbio de experiências. É nesses processos de atendimento que as práticas rotineiras dominam e são raramente questionadas de maneira regular e negociada. Porém, são causas habituais de acréscimos no custo: redundância de exames, exames inúteis e custosos, entre outros.

- A gerência e o conjunto de atividades estruturantes incluem a negociação com os financiadores e os fornecedores, a organização de atividades, a gestão de recursos humanos, o financiamento do investimento, os estudos de mercado, as escolhas tecnológicas e de tipo de serviços, etc.

- A atividade de suporte operacional é toda atividade logística que não corresponde a um fator-chave de sucesso para um dado segmento da atividade, mas que é necessária para a realização da prestação de serviço. Em geral, esta atividade corresponde à logística não-médica, passível de ser terceirizada porque não corresponde a um savoir-faire determinante no jogo concorrencial.

Os diferentes componentes de uma cadeia de valor não são independentes. Há conexões entre os vários componentes da cadeia de valor de um mesmo segmento e entre componentes de segmentos diversos. Esses componentes também apresentam interfaces com componentes da cadeia de valor de outras instituições com as quais a organização mantém relações de referência de pacientes, de fornecimento e compra de produtos ou de intercâmbio científico.

As vantagens concorrenciais seriam obtidas através da intervenção nessas interfaces, como o trabal ho no nível de cada componente gerador de valor. A exploração das interfaces é uma fonte importante de vantagens que subentende a existência de um bom sistema de comunicação/acompanhamento. Justamente por esse motivo, Crémadez inclui a logística médica e a comunicação informatizada como principais atividades operacionais.

Há inúmeros exemplos de exploração das interfaces: a saída de um serviço clínico e a entrada em outro; a relação emergência-serviços para o encaminhamento dos pacientes e a coerência de seu tratamento; a interface medicina- cirurgia em algumas patologias e atos, como a cancerologia, as hérnias de disco, a insuficiência coronariana, os transplantes, etc. e as relações de referência e contra- referência de pacientes com a rede.

O conhecimento da estrutura de custos dos segmentos é de fundamental importância para a definição de estratégias de obtenção de vantagens. A estrutura de custos de uma atividade se caracteriza de maneira sintética pela proporção de custos fixos de origem central, de custos fixos específicos e de custos variáveis. Os custos fixos mais importantes das atividades hospitalares correspondem à infra-estrutura de internação/alojamento, ao pessoal e às tecnologias implementadas

Quando a estrutura de custos de uma atividade revela uma preponderância dos custos fixos alocados sobre os custos fixos específicose os custos variáveis, seria interessante optar pela busca de vantagens estratégicas pelos custos. Quando se revela uma preponderância do custo variável unitário direto e de custos fixos específicos em relação aos custos fixos centrais alocados, seria necessário pensar em termos de diferenciação. A diversidade de atividades de um estabelecimento leva a adotar um mix de estratégias genéricas.

Em outras palavras e segundo nossa interpretação, a estratégia de custos, em geral, seria justificada, principalmente, quando os segmentos dependem de tecnologias e de infra-estrutura de internação custosas e compartilhadas (que não representam custos fixos específicos). I sso porque seria necessário considerar os recursos e minimizar a disputa de manei ra a garantir recursos para todos, o que demandaria uma racionalização, como, por exemplo, controlar o tempo de permanência, baixando custos. A não ser que 0 segmento apresente forte potencial de diferenciação, o fato de não contar com recursos próprios (ou potencial de captação desses recursos) que gerem custos fixos, como tecnologias, sugere que a estratégia de diferenciação não seria a melhor opção. Nesse caso, o investimento necessário em capacidade instalada, tecnologias e recursos humanos especializados representaria relativamente uma nota menor, devido ao baixo controle, diminuindo o escore resultante da análise de valor do segmento. 0 investimento ainda por ser realizado dificultaria a obtenção de vantagens comparativas via diferenciação. 


\section{A estratégia fundada nos custos}

M ostra-se imprescindível conceber uma estratégia de custos em todos os segmentos de atividade que precisam de infra-estruturas caras e compartilhadas, que apresentam um custo variável unitário pouco elevado e reduzidas formas de se diferenciarem expressivamente dos concorrentes.

Genericamente, a estratégia de custos consiste em privilegiar atividades que reforcem 0 potencial de sinergia já existente - atividades para as quais o controle dos custos compartiIhados é um savoir-faire determinante - e em eliminar custos específicos não justificados para garantir a conexão mais eficaz entre cadeias de valor.

0 controle do custo operacional dos recursos humanos supõe investimentos em formação e em organização. Para o pessoal paramédico recomenda-se uma formação polivalente e/ ou a criação de grupos polivalentes que permita uma maior flexibilidade na sua distribuição pela organização, garantindo de qualquer maneira um forte grau de aderência a cada serviço específico para onde foram destinados (uma posição intermediária entre a gestão global ou centralizada do corpo de profissionais e uma destinação rígida no interior de um). Para o pessoal médico recomenda-se uma formação que fomente uma visão multidisciplinar, assim como 0 estabelecimento permanente de contatos visando à formulação de consensos sobre as práticas profissionais.

Os custos de infra-estrutura são sensíveis à taxa de ocupação e de rotatividade, por um lado, eà adequação dos pacientes à vocação da estrutura, por outro. M aximizar a taxa de ocupação, o que dependeria, em boa medida, de estruturas menos rígidas, mais flexíveis, que se adaptem às evoluções do mercado, ao rendimento e à própria evolução da missão da organização, revela-se uma interessante estratégia de custos.

Com relação à rotatividade dos pacientes, para reduzir custos, seria necessário combater as práticas que provocam tempo alto de permanência (notadamente certas práticas rotineiras ligadas à entrada e saída de pacientes) e privilegiar estruturas de atendimento especializado, programado e de duração determinada, que explorem as sinergias entre atividades.

Regular as relações entre as estruturas técnicas de apoio diagnóstico e terapêutico e os serviços clínicos, levar em conta os pontos de estrangulamento não superáveis a curto prazo e recorrer eventualmente aos meios de parceiros externos também é conveniente.

A inadequação é fonte de desperdício de recursos e resulta, em boa medida, de serviços de triagem e de orientação que funcionam mal. A correspondência entre o tipo de clientela ea especialização da estrutura deve ter um grau de adequação conveniente.

U m elemento fundamental da redução de custos é o controle dos fluxos de pacientes que chegam e saem. U ma boa comunicação com os serviços que referenciam pacientes e com aqueles que complementam um cuidado é fator chave dessa estratégia.

\section{- Os custos tecnológicos}

O controle dos custos tecnológicos depende da oportunidade de aquisição de equipamentos a preços estáveis, conhecidos e que favoreçam um prazo curto de recuperação dos investimentos. Deve-se avaliar os riscos no caso de superposição de equipamentos nos diferentes concorrentes e evitar equipamentos ociosos ou semi-ociosos.

Deve-se considerar a concentração de equipamentos como fator de economias de escala e seu compartilhamento quando isso é necessário para atingir a massa crítica de atividade correspondente ao limiar de rentabilidade.

A aprendizagem da apropriação das tecnologias é fundamental. Todas as fases envolvidas na implementação de uma tecnologia, para além da mera manipulação, devem ser objeto de um treinamento que envolva um conjunto diversificado de pessoas, de modo a não ficar restrito ao operador da mesma. Esse processo deve envolver também o controle e a gestão do processo de substituição de uma tecnologia por outra.

0 ritmo de utilização dos equipamentos, organizado com a finalidade de evitar os custos adicionais decorrentes de flutuações (super ou subutilização), é outro fator importante no controle de custos tecnológicos, que depende de um bom controle da demanda e dos fluxos de chegada.

Outra estratégia fundada nos custos é a pesquisa de inovações tecnológicas capazes de diminuir o tamanho da infra-estrutura necessária e/ou de gerar uma substituição tecnológica que permita uma maior programação do atendimento, um controle crescente dos prazos de tratamento e uma tendência para formas de tratamento que impliquem tempos de interna- 
ção menores (cirurgia por videolaparoscopia, por exemplo).

\section{- Os custos variáveis}

Embora represente uma fração menor do conjunto de recursos alocados em um estabelecimento hospitalar, a margem de liberdade dos custos variáveis depende em grande parte de seu controle. A redução de tais custos depende, fundamentalmente, de duas questões.

1) Da gestão do abastecimento e de estoques, que depende do desenvolvimento de competências específicas:

- capacidade de negociação, fator importante de redução dos custos de abastecimento e que nem sempre é implementado devidamente. Baseia-se na seleção, conhecimento do mercado, prática da concorrência, utilização dos efeitos de tamanho e de escala nas compras;

- competência em explorar a sensibilidade da estrutura de custos dos fornecedores ao comportamento do cliente: estabilidade das especificações, prazos de pagamento, regularidade e volume dos pedidos unitários, etc. são fatores de redução dos custos dos fornecedores dos quais podemos tirar partido nas negociações;

- rigor na definição das especificações dos produtos comprados e, principalmente, na definição de seu acondicionamento unitário em função das práticas de consumo (de maneira a evitar o desperdício devido a acondicionamentos não adaptados, por exemplo).

2) Da formalização das práticas de atendimento e sua análise crítica regular. A implementação de rotinas profissionais éindispensável para controlar os custos variáveis, pois a formalização atuaria positivamente, em termos de eficiência, sobre os três componentes fundamentais dos custos variáveis: o consumo de atos, de produtos farmacêuticos e de material de consumo.

\section{Estratégias de diferenciação}

A competência médica específica, associada, em certos casos, ao controle de determinadas tecnologias éa via de diferenciação mais comum historicamente, mas não é e não deveria ser a única.

A diferenciação pode operar:

- modificando um ou vários elementos da cadeia de valor;

- explorando as relações entre os elementos das cadeias de valor de dois segmentos que apre sentam sinergias potenciais;
- modificando a conexão e a coordenação com os parceiros externos.

Os elementos acima podem ter um papel determinante na satisfação global do cliente.

\section{- Modificação da cadeia de valor de um segmento}

Esta estratégia pode consistir em introduzir um serviço complementar na cadeia de valor de um segmento. Desenvolvimento de cuidados paliativos no tratamento do câncer, por exemplo.

Completar ou modificar apenas um componente da cadeia de valor. A passagem de um "serviço-porta de entrada" (triagem) para a admissão direta pode ser uma via de diferenciação que questiona os elementos acesso, acolhimento, comunicação clientes-sistema de referência da cadeia de valor de vários serviços. A especialização tem pouco impacto se não se acompanhar de uma ampliação das relações com o sistema de referência que permita o recurso direto.

A criação de estruturas intermediárias concebidas para responder às necessidades dos pacientes fora da etapa aguda e para economizar recursos raros e custosos pode compensar a perda de flexibilidade induzida pela especialização.

$E$, ainda, uma maior colaboração com os parceiros externos pode evitar alongamentos indevidos das internações.

\section{- Modificação da conexão e coordenação entre dois segmentos que apresentam sinergias}

As relações entre dois segmentos com a finalidade de explorar novas sinergias podem ser remodeladas: estreitar os laços entre os médicos especializados e a cirurgia em torno da problemática dos transplantes ou entre a pediatria da nutriz e a obstetrícia para oferecer um serviço mais completo para as futuras mães e para gerar efeitos positivos no sentido do recurso posterior a este hospital no que concerne ao acompanhamento dos filhos.

\section{- Modificação da conexão e da coordenação com parceiros externos}

Significa o estabelecimento de parcerias visando: desenvolver pesquisa clínica; participar do ensino universitário ou de pós-graduação; diminuir o tempo de permanência; beneficiarse da transferência de tecnologia; suprir carências de equipamentos. 
0 grande desafio enfrentado por essa estratégia é a escolha de formas de diferenciação re lativamente menos custosas, em que o ganho em valor ou qualidade do serviço prestado supere os acréscimos em custo.

Pode-se acrescentar ainda, a focalização, que consistiria em recortar um segmento ou em privilegiar nesse segmento uma determinada categoria de usuário, de nosologia clínica ou de tipo de tecnologia de atendimento. Por exemplo, privilegiar um tipo deatendimento mais programável, referenciado (paciente ligado a uma determinada equipe), de natureza multidisciplinar.

Embora 0 enfoque de Porter dê a entender que as duas estratégias genéricas sejam exclusivas e se rejeitem mutuamente, há o indicativo de que mesmo na perspectiva de uma estratégia de diferenciação como estratégia predominante para um segmento de atividade torna-se necessário identificar a estratégia de menor custo relativo. Desse modo, podemos salientar a necessidade de que num universo complexo de atividades como o hospitalar se busque combinar de maneira inteligente as duas estratégias.

\section{0 caso da aplicação do enfoque na AP-4 da SMS/RJ como instrumento de coordenação regional}

Esta parte corresponde a uma experiência de consultoria realizada por técnicos do Departamento de Administração e Planejamento de Saúde da ENSP/Fiocruz e do Núcleo de Estudos em Saúde Coletiva (NESC) da Faculdade de Medicina da UFRJ. Esse trabal ho de aplicação do enfoque foi encomendado pela Coordenação da Área Programática n. 4 da SM S/RJ, envolvendo os três hospitais da área: Hospital Cardoso Fontes (HCF), Hospital Lourenço Jorge (HLJ) e H ospital Raphael de Paula Souza (HRPS), e se traduziu em parte de nossa tese de doutoramento (Artmann, 2002). 0 trabalho envolveu a especialidade de cirurgia geral dos três hospitais, visando a uma estratégia unificada e maior coordenação geral, por considerar essa especialidade um carro-chefe.

Por uma questão principal mente de espaço, não entramos em detalhes sobre o contexto e as características dos hospitais e sobre a dinâmica específica de aplicação do enfoque nos mesmos. Os planos específicos de ação também não são aprofundados. Limitamo-nos a apresentar, a título de exemplo: a segmentação escolhida pelos hospitais sem a fundamentação e a discussão ensejada; o escore do valor dos mesmos, ou seja, os pontos fortes e fracos de cada hospital no que diz respeito ao controle de Fatores-Chave de Sucesso; uma tentativa de comparação desses pontos considerando segmentos correlativos; uma leitura sintética dos portfolios dos hospitais; e as principais linhas de atuação estraté gica no sentido da complementaridade.

\section{0 valor dos segmentos dos hospitais}

Tomando o escore final do valor, representado pelo produto $\mathbf{P} \times \mathbf{N}$, no qual $\mathbf{P}$ é o peso relativo atribuído situacionalmente pelo grupo a cada critério (ver critérios de valor apresentados no item $\mathbf{M}$ étodo), e $\mathbf{N}$ a nota atribuída ao segmento considerando cada critério em cada segmento, o quadro 1 apresenta as prioridades de cada hospital em ordem decrescente.

Chama a atenção, no caso do H ospital Raphael de Paula Souza (HRPS), os baixos escores relativos atingidos pelos segmentos, com exceção dos procedimentos endoscópicos e, em uma escala inferior, da videocirurgia e da cirurgia geral do hospital-dia. Essa situação se explicaria pela dificuldade de captação de clientes decorrente de problemas de acesso geográfico e pela indefinição crônica da missão do hospital. Entre a problemática estratégica que esses valores deixam transparecer está: o potencial de captação de clientela regional e mesmo local relativamente baixo, que tem como correlato uma perspectiva pequena de crescimento dos segmentos, reforçada pela dificuldade de estabelecimento de parcerias externas; 0 baixo investimento relativo de vários segmentos; uma perspectiva de pouco domínio da concorrência eventual; e uma contribuição pouco expressiva dos vários segmentos para a missão geral do hospital, talvez reflexo de uma missão pouco definida ou de um projeto em que o grau de adequação da cirurgia geral não é muito claro.

Aos segmentos citados acima como mais valorizados (procedimentos endoscópicos, videocirurgia e hospital-dia), devemos acrescentar como prioridades relativas o de hérnias de parede. N os casos da videocirurgia, que se confunde com o segmento de vesícula e vias biliares (litíases), e das hérnias de parede, a intensidade da demanda na área, que força listas de espera no Hospital Cardoso Fontes (HCF) e H ospital Lourenço Jorge (HLJ), justifica serem assumidos como prioridades do HRPS.

Representam prioridades do $\mathrm{HLJ}$ os quatro segmentos mais valorizados: trauma, cirurgia 
Quadro 1

Prioridades dos hospitais para cirurgia geral

\begin{tabular}{|c|c|c|c|c|c|c|c|c|}
\hline \multicolumn{3}{|c|}{ H ospital Raphael de Paula Souza } & \multicolumn{3}{|c|}{ Hospital Lourenço Jorge } & \multicolumn{3}{|c|}{ Hospital Cardoso Fontes } \\
\hline & Segmentos & V & & Segmentos & V & & Segmentos & V \\
\hline 1. & Procedimentos endoscópicos & 16,5 & 1. & Trauma & 15,6 & 1. & Neoplasias & 15,3 \\
\hline 2. & Videocirurgia & 13,5 & 2. & Cirurgia endoscópica & 15,2 & 2. & Litíase & 14,6 \\
\hline 3. & H ospital/dia & 13,1 & 3. & N eoplasias & 14,1 & 3. & Pancreatite & 14,1 \\
\hline 4. & Hérnias de parede & 12,5 & 4. & Cirurgia fígado e vias biliares & 13,8 & 4. & Hipertensão porta & 13,9 \\
\hline 5. & V esícula e vias biliares & 11,9 & 5. & Emergências & 11,9 & 5. & Doenças da motilidade & 11,3 \\
\hline 6. & Patologias tubo digestivo & 11,1 & 6. & Hérnias de parede & 11,3 & 6. & Hérnias de parede & 11,3 \\
\hline \multirow[t]{4}{*}{7.} & Cirurgia de pescoço & 9,02 & 7. & $\begin{array}{l}\text { Cirurgia hospital-dia/ } \\
\text { ambulatório }\end{array}$ & 11,1 & 7. & $\begin{array}{l}\text { Hospital-dia e } \\
\text { cirurgia ambulatorial }\end{array}$ & 10,7 \\
\hline & & & 8. & Cirurgia ginecológica & 7,23 & 8. & Emergência traumática & 10,4 \\
\hline & & & & & & 9. & Emergência não-traumática & 9,19 \\
\hline & & & & & & 10. & Doença ácido-péptica & 9,2 \\
\hline
\end{tabular}

endoscópica, neoplasias e cirurgia de fígado e vias biliares.

As principais prioridades do HCF seriam dentro dessa lógica: neoplasias, litíase, pancreatite e hipertensão porta.

\section{Análise de pontos fortes e fracos dos hospitais tendo em vista o controle dos FCS}

\section{- Hospital Cardoso Fontes}

Considerando um controle dos FCS abaixo da nota 12 um ponto fraco (sistema de notação de 0 a 20), os vários segmentos seriam deficitários nos seguintes recursos ou FCS: articulação com a rede (parceria com Hospital Lourenço J orge e M iguel Couto) e área física (estes dois correspondendo a um baixo controle que compromete particularmente ao segmento de emergência em geral), anatomia patológica, CTI, leitos, laboratório de análises clínicas, videolaparoscópio, banco de sangue, sistema de transporte de pacientes e de comunicação, comprometendo particularmente a emergência.

Os pontos fortes correspondem ao alto ou muito alto nível de controle da endoscopia e do setor de imagem. Considera-se, todavia, a disponibilidade e capacitação dos cirurgiões e anestesistas um ponto forte, embora ainda faltem cirurgiões para cobrir as necessidades de vários segmentos (necessidade mais evidente no segmento de hérnias) e an estesistas no segmento de emergências em geral.

A videolaparoscopia éum FCS bem controlado no caso das neoplasias, porém não sufi- ciente para dar conta das necessidades dos outros segmentos que dela se utilizariam em potencial. Considera-se, todavia, que haveria uma carência no que tange à tomografia e imagem no segmento de emergência em geral.

Podemos questionar a posteriori, à luz da listagem de FCS do segmento de neoplasias do HLJ, a não definição pelo HCF do tratamento complementar como FCS desse segmento. Em relação a este, cumpre esclarecer que o hospital apresenta um bom domínio da quimioterapia, não assim da radioterapia, que teria que se resolver através de parcerias formalizadas.

A ordem decrescente da posição competitiva dos segmentos (o escore da posição competitiva éo produto $\mathbf{P} \mathbf{x} \mathbf{N}$, em que $\mathbf{P}$ éo peso relativo de cada FCS e $\mathbf{N}$ a nota correspondente ao controle atual de cada FCS) é apresentada a seguir:

1. Cirurgia ambulatorial/hospital-dia e tumores de partes moles (escore: 20 )

2. Doenças da motilidade (escore: 15,55 )

3. Tumores de aparelho digestivo e glândulas endócrinas (escore: 13,8)

4. Doença ácido-péptica (escore: 13,7 )

5. Hipertensão porta (escore: 13,55)

6. Pancreatite (escore: 13,1 )

7. Litíases (escore: 13,05)

8. Hérnias de parede (escore: 12,4)

9. Emergência traumática (escore: 11,1)

10. Emergência não-traumática (escore: 10,4)

O nível de competitividade do HCF, avaliado pelo controle dos FCS dos vários segmentos é alto, pois pelo menos sete segmentos apresentam um escore superior a 13 (treze). 0 grau de controle dos FCS do HD é o máximo possível, 
embora, como se depreende da análise do valor, este segmento não constitui uma prioridade de desenvolvimento, o que sugere um tratamento estratégico de simples manutenção. Os segmentos prioritários do hospital (neoplasias, litíases, hipertensão porta e pancreatite) revelam uma posição competitiva boa, porém distante ainda do ideal, o que sugere a necessidade de um esforço de investimento ou de apropriação dos FCS significativo, variável segundo a demanda específica de cada segmento, de modo a melhorar o nível de qualidade geral do hospital.

\section{- Hospital Raphael de Paula Souza}

Os pontos fracos do controle de FCS se referem à não disponibilidade de CTI, à falta de próteses, à falta de dosagens hormonais (para cirurgia de pescoço), à carência de pessoal de apoio e de radiologia, à insuficiência da equipe de endoscopia, à fal ta de enfermeiras no centro cirúrgico e nas enfermarias e ao insuficiente fluxo de insumos. Também devemos registrar aqui carências relativas ao equipamento de radiologia/ultra-sonografia. Outro ponto fraco de grande importância se refere à inexistência de uma política clara de captação de pacientes, que compense as dificuldades de acesso da instituição, afetando a maioria dos segmentos.

Os pontos fortes do hospital estão representados pela equipe cirúrgica, as enfermarias, os equipamentos de videocirurgia e de procedimentos endoscópicos e o centro cirúrgico.

A posição competitiva dos segmentos é a seguinte na ordem decrescente, em função dos escores específicos:

1. Hérnias da parede abdominal com internação $(13,9)$

2. H ospital-dia: hérnias de parede abdominal e cirurgia de pequeno porte $(13,9)$

3. Videocirurgia $(12,94)$

4. Procedimentos endoscópicos $(11,86)$

5. Cirurgia de pescoço $(11,74)$

6. Patologias de tubo digestivo $(11,65)$

7. Vesícula e vias biliares $(11,05)$

A competitividade dos vários segmentos do hospital é intermediária. Os únicos segmentos que apresentam uma competitividade relativamente mais alta são o de hérnias de parede, cirurgia de hospital-dia e videocirurgia. A falta de terapia intensiva é um fator que compromete 0 desempenho de qualidade dos segmentos de maior complexidade relativa e que coloca em questão a adequação da cirurgia geral no hospital. U m fator-chave de sucesso a ser explorado de maneira premente é, por outro lado, o desenvolvimento de parcerias externas e formas de captação de clientela, que contribuam para melhorar a competitividade do hospital.

\section{- H ospital Lourenço Jorge}

Entre os pontos fortes da especialidade no que diz respeito ao controle dos FCS devem registrar-se: a equipe médico-cirúrgica, a sala de trauma, a emergência aberta 24 horas, os equipamentos para videocirurgia e procedimentos endoscópicos (incluindo os do segmento de cirurgia ginecológica), o suporte de enfermaria, do CC, do CTI e da UI para vários segmentos, e o apoio da tomografia computadorizada e do setor de imagem para neoplasias e fígado.

Há problemas no que diz respeito ao suporte da imagem e da tomografia computadorizada nos segmentos de emergência e de trauma; da mesma maneira, o suporte do CTI ao segmento de trauma parece insuficiente.

Os pontos fracos seriam principalmente: a falta de parcerias para tratamento de quimioterapia e radioterapia, a fal ta de exames laboratoriais específicos para os segmentos de fígado, neoplasias e cirurgia ginecológica, deficiências relativas ao banco de sangue, falta de material cirúrgico específico e de insumos para alguns segmentos (como fígado), deficiências da endoscopia terapêutica no segmento de fígado, o fornecimento irregular de próteses, a falta de pessoal e limitação da área física do H ospitaldia, e a falta de parcerias com especialidades ligadas ao trauma, não disponíveis no hospital.

O escore da posição competitiva dos segmentos é o seguinte na ordem decrescente:

1. Cirurgia endoscópica $(15,36)$

2. Emergências $(15,3)$

3. Hérnias $(15,25)$

4. Trauma $(14,5)$

5. Neoplasias $(12,9)$

6. Cirurgia ginecológica $(12,9)$

7. Hospital-dia e cirurgia ambulatorial $(12,75)$

O nível de apropriação dos FCS dos segmentos é alto, destacando-se, na ordem decrescente, a cirurgia endoscópica, as emergências, as hérnias de parede e o trauma. D evemos lembrar que o segmento de cirurgia endoscópica e o de trauma aparecem entre os quatro mais priorizados, segundo a análise do valor. 0 segmento de neoplasias, um dos mais valorizados, apresenta uma competitividade razoável, porém inferior à competitividade do HCF, o qual apresentaria condições para um melhor desen- 
volvimento desse segmento na perspectiva de centro de referência.

0 fato de a segmentação dos hospitais ser situacional, o que significa estar orientada pelas capacidades distintivas e as necessidades estratégicas de desenvolvimento de cada um, assim como pela sua particular organização do trabaIho (e o olhar particular dos profissionais), representa uma dificuldade para comparação direta do grau de apropriação relativa dos FCS pelos hospitais.

Embora os segmentos não sejam exatamente os mesmos, uma comparação pode ser tentada a partir do estabelecimento de correlações entre os segmentos. Isso significa tentar comparar os segmentos que mais se aproximam em termos de conteúdo da atividade e de utilização de FCS conexos ou similares. Em relação à experiência em pauta, as seguintes correlações de segmento podem ser feitas a título de uma tentativa de comparação:

- entre as emergências (não-traumáticas) do HCF e do HLJ;

- entre a emergência traumática do HCF e do HLJ;

- entre as hérnias de parede dos três hospitais;

- entre os segmentos de litíase do HCF, de cirurgia endoscópica do $\mathrm{HLJ}$ e e videocirurgia do HRPS. No caso do HRPS, observamos que 0 elenco dos FCS dos segmentos de vesícula e vias biliares e de videocirurgia é semelhante, com a única diferença do registro do equipamento como FCS da videocirurgia, de modo que não haveria maiores problemas. Em relação ao HLJ, o segmento de fígado e vias biliares inclui um enfoque de suporte clínico referido ao fígado e a entidade Ca de fígado, de modo que fica mais difícil estabelecer a equivalência com a entidade cálculos biliares. Considerando ser a videolaparoscopia uma tecnologia que se aplica predominantemente a essa entidade na especialidade específica, parece possível a correlação, com reservas;

- entre o segmento de neoplasias do HCF e do HLJ;

- entre os segmentos Hospital-dia dos três hospitais (esta análise comparativa não foi feita, por considerar-se que o segmento respectivo não seria objeto de concorrência maior)

Terminaremos esta parte, com a apresentação de resultados exploratórios sobre uma comparação dos segmentos correlacionados:

1. Emergências: o HLJ $(15,3)$ apresentaria uma melhor competitividade do que o HCF $(10,4)$, com quase 5 pontos de diferença. O HCF apre- sentaria vários pontos fracos, correspondendo a uma nota de 10 para baixo: falta de anestesistas, área física insuficiente, deficiências no setor de imagem/tomografia, insuficiente equipamento de videolaparoscopia, inadequado sistema de transporte de pacientes e de comunicação, e falta de parcerias com hospitais de emergência (HLJ e Miguel Couto). O HLJ deve sua posição favorável, em boa medida, à disponibilidade e capacitação da equipe médica e ao sistema de plantão 24 horas. 0 único ponto fraco relatado corresponde ao setor de imagem/tomografia (nota 10$)$.

2. Emergência traumática: o controle dos FCS do HLJ é bastante mais favorável $(14,5)$, relativamente ao HCF $(11,1)$. 0 HCF relata os mesmos pontos fracos do segmento de emergência não-traumática, acrescidos de deficiências no banco de sangue. $0 \mathrm{HLJ}$ apresentaria alguns pontos fracos: imagem/tomografia, banco de sangue, CTI/UI, e parcerias com outros hospitais. Os FCS mais controlados, que ajudam a sua diferenciação como segmento, são a qualidade da equipe médica e a sala de trauma. Esta situação é uma alternativa para o HCF, que não prioriza o trauma, representando o HLJ uma oportunidade clara de colaboração.

3. Neoplasias: a diferença de um ponto a favor do $\operatorname{HCF}(13,8)$ não reflete bem a diferença entre os dois hospitais. $\mathrm{O} \mathrm{HCF}$ tem uma tradição maior no campo das neoplasias, embora tenha perdido alguns acúmulos como o laboratório de marcadores tumorais, Fator-Chave de Sucesso que o hospital tem amplas condições de recuperar. Sua produção também é relativamente mais expressiva. Os pontos fracos do HCF sereferem à falta de cirurgiões e de anestesistas para dar conta da demanda real e potencial do segmento, e às carências do setor de anatomia patológica, como a falta de imuno-histoquímica, e do laboratório de análises. O HCF apresentaria um maior controle relativo dos equipamentos envolvidos no segmento (imagem, videolaparoscopia e endoscopia) e de parte do tratamento complementar, correspondente à quimioterapia, que erradamente não aparece como FCS explicitado pela equipe correspondente. Em boa parte, o controle deste FCS por parte do HCF justifica uma ampliação significativa da diferença em favor do HCF.

4. Litíases HCF/cirurgia endoscópica H LJ/videocirurgia do HRPS. $0 \mathrm{HLJ}(15,36)$ e o HCF $(13,05)$ apresentam um al to controle dos FCS do segmento envolvido, não se verificando 0 mesmo em relação ao HRPS, com um desem- 
penho intermediário. Este último vê sua posição enfraquecida pela falta de CTI, pela falta de enfermeiras, auxiliares de enfermagem e pessoal de apoio, pela insuficiência do setor de imagem/ radiologia e de ultra-sonografia, pelo fornecimento irregular de insumos e pela baixa captação de pacientes. 0 H LJ apresentaria como pontos fracos: a carência relativa de leitos para o segmento, a insuficiência do setor de imagem/radiologia e ultra-sonografia e o fornecimento irregular de próteses. E como ponto mais forte, sua equipe médica. 0 HCF refere como pontos fracos: a falta relativa de cirurgiões, a insuficiência do setor de anatomia patológica, o suporte insuficiente do CTI e a disponibilidade de videolaparoscópio para o segmento. Este é um setor com fila de espera no $\mathrm{HCF}$ e no HLJ.

5. Hérnias de parede: $\mathrm{OHLJ}$ aparece primeiro em termos de posição relativa (15), seguido pelo HRPS $(13,9)$ e pelo HCF $(12,4)$. Se nenhum desses desempenhos pode ser catalogado, de maneira significativa, como desfavorável, chama a aten ção o escore favorável do H RPS, onde este segmento constitui uma das prioridades mais marcantes, ao mesmo tempo em que os outros hospitais têm listas de espera para o segmento. Os pontos fracos do HCF são: falta relativa de cirurgiões, de leitos e de instrumental de videolaparoscopia. No caso do H LJ, que tem um controle elevado dos FCS pertinentes (com destaque para sua equipe médica e o fluxo de pacientes), seu único ponto fraco é o fornecimento irregular de próteses, por vezes até a suspensão do material. No HRPS, os pontos fracos são: a falta de pessoal paramédico, o fornecimento irregular de insumos e a baixa captação de pacientes. Seus pontos fortes mais destacados são a equipe médica, as salas de centro cirúrgico e a disponibilidade de próteses.

$M$ ais do que fazer comparações, ou buscar homogeneizar a segmentação, particularmente nesta experiência de aplicação do método, o objetivo foi construir um plano comum para a área/região, a partir dos planos de cada hospital, confrontando e discutindo amplamente as diferenças.

A idéia de organização da informação, de modo a permitir uma comparação, traz uma possibilidade de discussão rica que pode levar a retificações, validações, acréscimos de informação e consensos que ajudem a gerar uma visão mais clara das potencialidades de cada hospital em termos de resposta às demandas/necessidades de saúde (Artmann: 2002).

\section{A leitura do portfolio de atividades como base para a estratégia}

O portfolio, como já dito, é um gráfico de bolhas que implica o cruzamento de três variáveis: escore final do valor dos segmentos (de 0 a 20), posição competitiva ou grau de controle dos FCS por segmento (de 0 a 20) e o volume de produção de atividades. N este último caso, consideramos uma média mensal.

A seguir fazemos uma interpretação dos portfolios anexos dos hospitais.

HLJ - um portfolio bem adaptado e de pouco risco estratégico, pois os segmentos apresentam um valor acima da média, mostrando uma boa adequação à missão do hospital, euma missão competitiva com escores elevados. N enhum segmento está fora do quadrante superior direito. Os segmentos menos valorizados são: HD e cirurgia ambulatorial, hérnias de paredee emergências. D estes, as hérnias de parede e as emergências apresentam uma boa posição competitiva (alta), e o HD, uma posição mais intermediária. 0 volume de produção desses segmentos é relativamente alto, acima de tudo, o volume das emergências. Essa situação recomenda um tratamento estratégico de manutenção dos segmentos (nos níveis de produção atual), que implique transferir parte da tecnologia e dos pacientes para hospitais de menor demanda, como o HRPS, para equacionar o problema eventual das filas em alguns segmentos, como hérnias. Os segmentos mais valorizados são trauma e cirurgia endoscópica, que também apresentam uma alta posi ção competitiva, o querecomenda um tratamento estratégico de expansão para absorver parte da clientela do HCF, que não valoriza trauma. $N$ eoplasias tem uma alta val oração, uma posição competitiva mais intermediária, e um volume de produção pequeno, bem abaixo dos outros segmentos. Dada a posição competitiva potencial mais favorável do HCF, justifica-se um trabalho de parceria com o mesmo, que não implique investimentos elevados em procedimentos especializados, que seriam concentrados no H CF (manuten ção). Em relação a fígado supõe-se a necessidade de uma expansão, pelo conhecimento tecnológico acumulado pelos profissionais e a perspectiva de cobrir áreas de atendimento mais especializado em nível regional. Do portfolio, foi retirado o segmento de cirurgia ginecológica, por haver questionamentos sobre sua inserção na cirurgia geral e por haver desinteresse e falta de recursos que justifiquem sua expansão (deses- 
tímulo). Em geral, este é um hospital que tende para uma complexidade maior, sem perder sua natureza de hospital com um forte conteúdo de emergência.

HCF - o portfolio apresenta uma maior diversificação relativa de atividades, de maior nível de especialização ou complexidade. Em termos de competitividade, este portfolio apresenta também um baixo risco estratégico, pois a maior parte dos segmentos tende a se distanciar da média, com exceção da emergência traumática, e, em escala um pouco menor, da emergência não-traumática, segmentos que o hospital também não valoriza. 0 grau de adequação dos segmentos não é tão claro, na medida em que além das emergências, o segmento de úlcera ácido-péptica e o próprio HD são medianamente valorizados. N este último caso, chama a atenção a extremamente al ta posição competitiva do segmento. Isso sugere uma situação de inadaptação ao perfil desejado para o hospital, e de insuficiente difusão tecnológica. Pelo seu volume de produção, a estratégia de manutenção éa mais adequada, transferindo se possível e de maneira paulatina parte da clientela para outras estruturas. Em relação aos outros segmentos potencial mente inadaptados, justifica-se uma estratégia de manutenção ou recorte (neste caso, do trauma, que seria em parte absorvido pe(o $\mathrm{HLJ}$ ). Os quatro segmentos mais valorizados (tumores, litíase, pancreatite e hipertensão porta) podem ser objeto de uma estratégia de expansão, de maneira mais clara os de maior produção: litíases e tumores. Sobre este último, há uma base forte de consenso na área e na Secretaria M unicipal de Saúde (pelo menos na época da experiência) de que o HCF deveria investir na perspectiva de um centro de referência intermediário em neoplasias. Finalmente, em relação às hérnias de parede, não se poderia pensar pelo volume da demanda em um recorte ou diminuição em nenhuma estrutura da área. Ao contrário, pensar na expansão do segmento nos três hospitais, explorando as parcerias entre eles, não é uma estratégia despropositada.

H RPS - os segmentos de maior risco estraté gico são vesícula e vias biliares, cirurgia de pescoço, patologias de tubo digestivo e procedimentos endoscópicos, com uma posição competitiva um pouco acima da média, mas em uma situação pouco discriminante no que diz respeito ao controle de fatores-chave de sucesso e pouca produção. N essa situação, convém estimular ou expandir os segmentos mais adaptados ou de maior valor relativo e de maior produção: hér- nias, HD e cirurgia videolaparoscópica. Já fizemos referência anteriormente ao valor relativamente mais baixo dos segmentos deste hospital em função de toda uma problemática estratégica, que diz respeito à captação de clientela, a uma dificuldade maior na definição da missão e ao desestímulo ao desenvolvimento de segmentos representado pela falta de terapia intensiva. Sem equacionar esses problemas, édifícil pensar na expansão de vários segmentos. De qualquer modo, justifica-se uma estratégia de apoiar o hospital nas áreas indicadas para descongestionar as filas de espera dos outros hospitais.

Da leitura dos portfolios e da sugestão de linhas estratégicas depreendemos al gumas linhas de complementaridade, que já vêm se perfilando à luz da análise prévia.

- Parceria dos hospitais em torno do eixo das neoplasias, centralizado no HCF como referência da área. Para tal, os três hospitais reivindicam equipar a anatomia patológica do $\mathrm{HCF}$ com histoquímica, equipar o laboratório com marcadores tumorais e equacionar, através de investimento próprio ou de convênio, o tratamento complementar de radioterapia.

- Parceria em torno do pólo de trauma, representado pelo HLJ. 0 fortalecimento desse pólo implica investimentos físicos, melhora do suporte de imagem e parcerias com o H ospital M iguel Couto e o HCF para encaminhar pacientes de neurocirurgia, de cirurgia vascular, torácica, urológica, etc. Há um consenso em relação à aquisição de um tomógrafo helicoidal, a ser instalado em um hospital da área, destinado a servir aos três.

- Expansão de segmentos do HRPS para escoar parte da clientela dos outros dois hospitais em filas de espera (hérnias, cirurgias de pequeno porte, litíases, etc.).

- M elhora significativa do sistema de comunicação e de transporte de pacientes e dos mecanismos formais de articulação da rede, etc.

- Implantação da terapia intensiva no HRPS como condição de possibilidade para receber a clientela em fila de espera dos outros hospitais. - Os hospitais estabeleceram um consenso em relação à necessidade de implantar uma política descentralizada de sangue na área (FCS carente que apóia a emergência fundamental mente). Sustenta-se a necessidade de definir uma política de captação e distribuição adequada de sangue para área, e os três hospitais propõem por consenso reequipar o banco de sangue do HCF visando ser referência na área, porém apoiando de maneira orgânica o banco do HLJ. 
- Há um consenso entre os hospitais em relação à necessidade de uma política descentralizada de manutenção preventiva dos equipamentos e de regularização do fluxo de insumos gerais e específicos, definidas como áreas-problema comuns.

- Propõem as ações necessárias de incorporação de pessoal definidas como necessidades de apropriação dos FCS pertinentes pelos hospitais e ações comuns de capacitação, centradas nas técnicas de videolaparoscopia.

- Os três hospitais defendem a implantação de um sistema de hierarquização sanitária que passe pelo aumento da capacidade resolutiva da rede básica, para descongestionar o hospital, e pelo estabelecimento de uma rede de referência e contra-referência na área, incluindo a colaboração horizontal entre hospitais.

\section{Considerações finais}

0 caso em questão é revelador da possibilidade concreta de al cançar um consenso fundamental em torno de uma política de colaboração hospitalar no nível local e regional. É inegável que essa possibilidade depende da capacidade de mobilização e de comunicação dos coletivos dos hospitais, articulada ao grau de compromisso demonstrado pelas lideranças locais em relação à colaboração. Reiteramos ser uma condição para a negociação de estratégias comuns a necessidade de um projeto hospitalar explícito, que seja fruto de uma discussão interna, que gere contratos ou compromissos.

A démarche stratégique é um enfoque que pode ser adaptado como instrumento de apoio ao Processo de Programação Pactuada Integrada, previsto como instrumento básico da NOAS. Entendendo esse processo como uma dinâmica de entrosamento baseada em projetos das várias unidades hospitalares e ambulatoriais de uma região, sugere-se que os projetos hospitalares se baseiem nas grandes categorias do enfoque da démarche, quais sejam: uma definição clara das prioridades em termos das especialidades e dos segmentos de produção das especialidades, que suponha uma valorização dos mesmos, que dependa de critérios estratégicos que permitam estabel ecer comparações, e uma definição dos pontos fortes e fracos dos segmentos produtivos, concebidos do ponto de vista do controle de seus FCS. Acreditamos que a partir dessas definições é possível sustentar processos de discussão que possibilitem acertos fundamentais a respeito de uma política comum que considere perfil epidemiológico da área/região e critérios de incorporação racional de tecnologias, capacitação de recursos humanos e investimentos necessários não só do ponto de vista econômico stricto sensu, mas também em controle, avaliação e gestão.

Entendemos que essa dinâmica de aplicação adaptada viria fortalecer o âmbito de atuação instrumental microgerencial, ajudando a promover um fluxo de informação e de formulação de baixo para cima, regulado centralmente, que contribuiria decisivamente para a geração de compromissos reais de mudança em busca de maior qualidade no atendimento eacesso da população que dele necessita. Sem esse movimento, a questão do compromisso seria controversa.

U m tema caro ao planejamento, e conseqüentemente objeto de propostas de mudanças, como a pretendida na busca da construção de uma rede hierarquizada e regionalizada e que atenda, de fato, às necessidades (expressas ou não) de saúde da população, é a relação necessariamente dialética entre centralização versus descentralização (M atus, 1993). N em sempre o ol har que se pretende total izante e conhecedor da problemática mais global e dita estratégica consegue dar conta das problemáticas específicas das diferentes regiões (considerando um país de tão grandes desigualdades), quanto mais de questões relacionadas à gestão do micro, incluindo instituições e atores diversos. Por outro lado, o hospital tende a fechar-se sobre sua problemática interna, os diferentes atores intra-institucionais, os diversos profissionais de saúde e de apoio prendem-se muitas vezes a defesas corporativas de espaço e recursos, sem levar em conta uma perspectiva estratégica mais ampla. Isto vale para os processos de planejamento/pactuação internos a uma mesma instituição, aos que pretendem dar conta da rede, das regiões ou microrregiões e da alocação mais justa e equitativa de recursos. Existem problemas que devem ser equacionados a partir de uma visão mais ampla, de país, e que devem ser alvo de regulação mais direta pelo nível federal e outros para os quais a autonomia local deve ser preservada e possibilitada para construir a adesão necessária dos atores concretos aos projetos. Somente a explicitação de critérios e objetivos e a contrapartida em termos de avaliação e cobrança de resultados poderá trazer transparência e coerência para os projetos de investimento. 
A démarcheéum instrumento estratégico de gestão da clínica que retira seu potencial da capacidade de refletir a partir da micropolítica e microeconomia dos processos de trabalho, dos segmentos de produção concretos e de sua problemática estratégica e de mobilizar nesta reflexão os atores principais que estabelecem elos diretos com os usuários do sistema.

Como propõe uma análise multicritérios e enseja uma ligação entre a direção estratégica do hospital e os profissionais da ponta, bem como a abertura do hospital para o ambiente esua inserção na rede, permite a construção de projetos regionais coerentes com as necessidades/ demandas (que entram como critérios) e que devem, necessariamente, considerar as políticas mais amplas de instâncias reguladoras, como 0 Ministério da Saúde. Permite contribuir também para questionar e rever algumas destas políticas.

Alguns desafios se impõem:

- A necessidade, no atual cenário, de aprofundar a discussão sobre as relações público versus privado, no sentido de ampliar a possibilidade de oferecer à população, aos cidadãos, um atendimento de qualidade em todos os níveis de complexidade (Artmann, 2002).

- A necessidade de maior envolvimento dos atores dos níveis centrais, na tentativa de ampliação da governabilidade sobre os planos, conjugando esta questão com a pesquisa sobre habilidades de liderança e nego ciação (Rivera \& Artmann, 1999)

- A utilização mais sistemática de métodos/ enfoques de prospectiva, análise ainda incipiente e que consideramos extremamente importante para definição estratégica dos al vos de investimentos.

- 0 investimento em capacitação gerencial em todos os níveis do sistema (em gestão estratégica) para que o planejamento e a programação sejam frutos de real pactuação e não apenas um desenho que faz parte de um ritual que visa à captação de recursos.
Com relação a esteúltimo desafio, vale a pena ressaltar que 0 enfoque da démarche straté gique enfatiza a necessidade de passar para as equipes do hospital a "tecnologia método", por isso a importância e envolvimento dos profissionais na discussão e construção do projeto. I gualmente importante é a necessidade de que a experiência perdure no tempo visando ao objetivo da mudança cultural e ao próprio aprendizado sobre uma nova forma de "planejar", construindo projetos de maneira mais coletiva e, portanto, agregando adesão dos diversos atores e maior governabilidade. Poderíamos nos referir à aprendizagem organizacional, que supõe um constante aprender a aprender.

Essa estratégia é fundamental para a apropriação, pelo sistema, de conhecimentos e métodos relevantes para a tomada de decisão e para a gestão. Os gestores deveriam depender cada vez menos de consultores externos e adquirir capacidade de manejar metodologias mais complexas condizentes com a complexidade das situações reais que enfrentam. Por outro lado, o recurso consultoria será sempre importante num contexto de fragmentação/especialização do conhecimento e necessidade de vencer frontei ras disciplinares em direção à interdisciplinaridade. Contudo, é um recurso que deve ser utilizado estrategicamente, em momento e áreas específicas para que não gere desperdício e dependência, mas tenha um impacto positivo e amplo na instituição e no sistema, incluindo a incorporação de novos saberes e fazeres.

Por último, enfatizamos que as estratégias de diferenciação e de custos podem permitir um uso mais racional de recursos, num contexto de rápidas mudanças tecnológicas, de inovações e de mudança do perfil epidemiológico num país cuja população envelhece e exige cada vez mais altos investimentos em saúde, ao mesmo tempo em que mantém a necessidade dos investimentos tradicionais. 
Figura 1

Portafólio Cirurgia Geral - Hospital Lourenço J orge

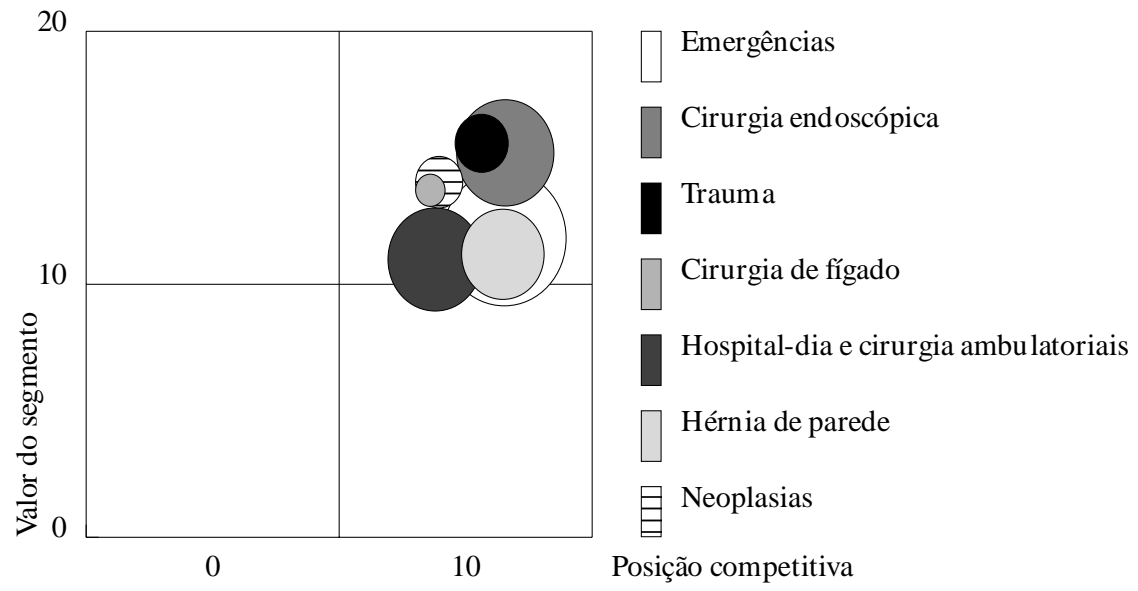

Figura 2

Portafólio Cirurgia Geral - Hospital Raphael de Paula Souza

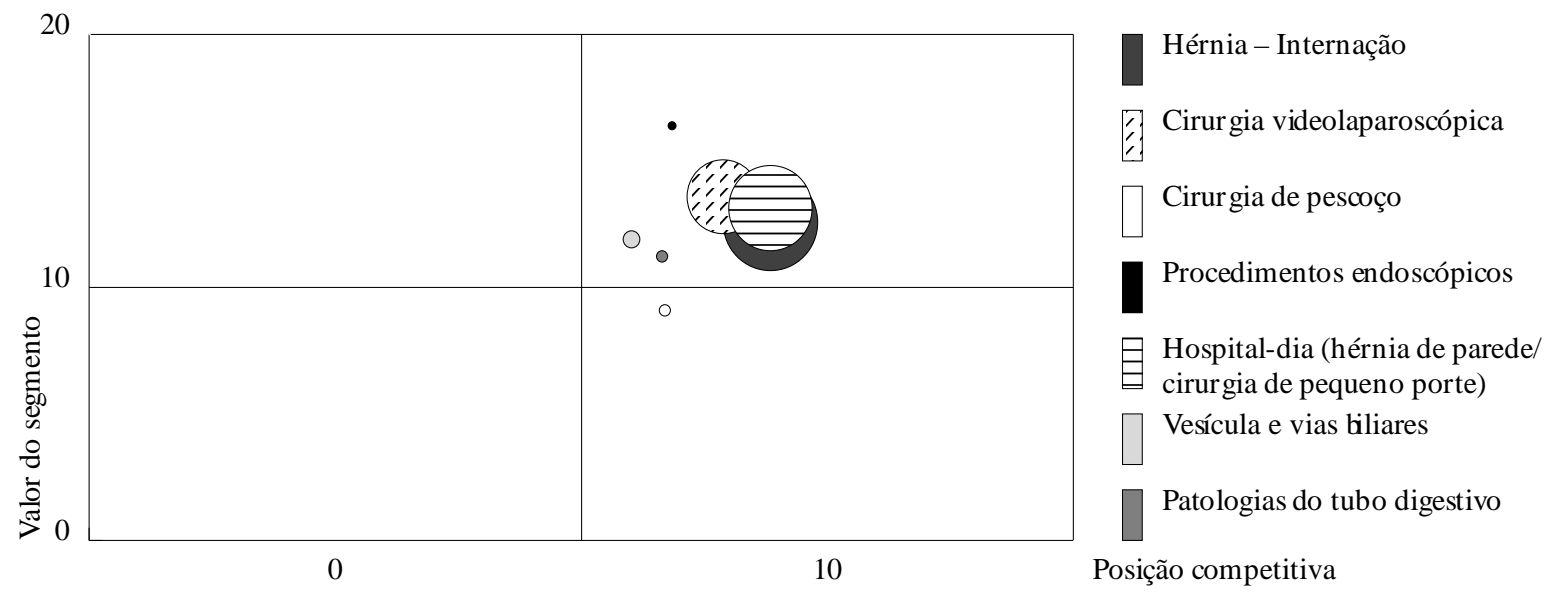


Figura 3

Portafólio Cirurgia Geral - Hospital Cardoso Fontes

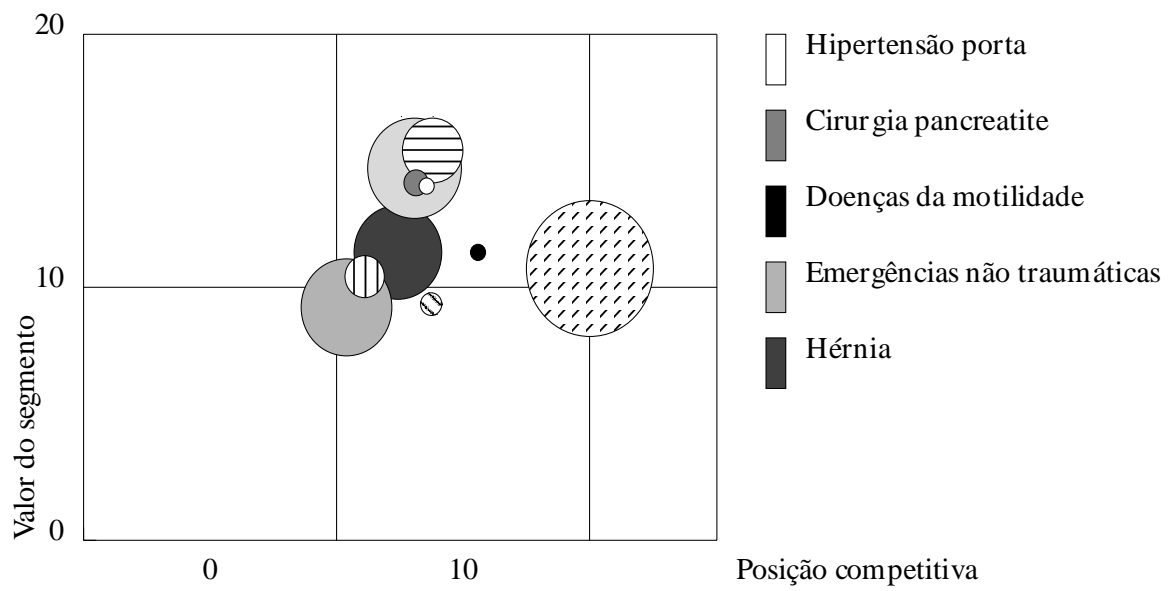

Litíase

日 Tumores

Cirurgia ambulatorial/ $\checkmark$ tumor partes moles

Emergência traumática

N Doença ácido-péptica

Posição competitiva 


\section{Referências bibliográficas}

Artmann E 2002. Démarche stratégique (gestão estratégica hospitalar): um enfoque que busca a mudança através da comunicação e solidariedade em rede. Tese de doutorado. Departamento de M edicina Preventiva, Faculdade de Ciências M édicas, Unicamp, Campinas.

Artmann E 2002a. Enfoque da démarche stratégique na gestão hospitalar. In M CS M inayo \& SF Deslandes (org.). Caminhos do pensamento, epistemologia e método. Fiocruz, Rio de Janeiro.

Crémadez M \& Grateau F 1992 (1a ed.) e 1997 (2ąed.). Le management stratégi que hospitalier. Inter Éditions, Paris.

Crozier M \& Friedberg E 1977. L'acteur et le système. Éditions du Seuil, Paris.

Détrie JP (org.), Strategor 1997. Stratégie, structure, décision, identité: politique générale d'entreprise. Dunod Ed., Paris.

Lawrence PR \& Lorsch JH 1973. Adapter les structures de I'entreprise. Éditions d'Organisation, Paris.

Lopes CM B 1997. 'D émarche' estratégica: uma metodologia a ser proposta para a gestão hospitalar brasileira. Dissertação de mestrado. Escola N acional de Saúde Pública, Fiocruz, Rio de Janeiro.

M atus C 1993. Política, planejamento e governo. I pea, Brasília.

M erhy E 2000. Reflexões sobre as tecnologias não materiais em saúde e a reestruturação produtiva do setor: um estudo sobre a micropolítica do trabalho vivo em saúde. Tese de livre docência. D epartamento de M edicina Preventiva, Faculdade de Ciências M édicas, U nicamp, Campinas.

M inistério da Saúde 2002. Regionalização da assistência à saúde: aprofundando a descentralização com eqüidade no acesso. N orma O peracional da Assistência à Saúde N OAS-SU S 01/02 (Portaria M S/GM n. 373, de 27/01/2002). Brasília.
M intzberg H 1982. Structure e dynamique des organisations. Éditions d'Organisation, Paris.

NiocheJP \& Poinsard R (eds.) 1978. L'évaluation des politiques publiques. Ed. Economica, Paris.

Porter ME 1982. Choix sratégiques et concurrence. Ed. Economica, Paris.

Rivera FJU 1997. A "démarche" estratégica: a metodologia de gestão do Centro Hospitalar Universitário de Lille, França. Cadernos de Saúde Pública 13(1):73-80.

Rivera FJU 1998. O enfoque de integração estratégica de Crémadez e Grateau ea gestão de recursos tecnológicos e humanos. Revista de Administração Pública 32(6):179-208.

Rivera FJU \& Artmann E 1999. Planejamento e gestão em saúde: flexibilidade metodológica e agir comunicativo. Ciência \& Saúde Coletiva 4(2):355-365.

Souza RM P 1997. A démarche estratégica: uma abordagem teórico-metodológica. Dissertação de mestrado. Escola Nacional de Saúde Pública, Fiocruz, Rio de Janeiro.

Thevènet M 1993. Audit de la culture d'entreprise. Éditions d'O rganization, Paris.

UAS-CHRU (U nité d'Analyse Stratégique - Centre H ospitalaire Régional Universitaire) 1995a. La démarche stratégique. Guide M éthodologique. M aterial Instrucional. UAS-CHRU, Lille. (Mimeo).

UAS-CHRU (Unité d'Analyse Stratégique - Centre H ospitalaire Régional U niversitaire) 1995b. La démarche stratégique. Sommaire. M aterial Instrucional. UASCHRU, Lille. (M imeo).

Artigo apresentado em 10/10/2002

Aprovado em 30/11/2002

Versão final apresentada em 10/12/2002 